\title{
Predictors of hospitalization and institutionalization in Medicaid patient populations with Alzheimer's Disease
}

\author{
Adrienne M. Gilligan, Daniel C. Malone*, Terri L. Warholak, Edward P. Armstrong \\ College of Pharmacy, Department of Pharmaceutical Sciences, University of Arizona, Tucson, USA; \\ *Corresponding Author: malone@pharmacy.arizona.edu
}

Received 2 April 2013; revised 15 May 2013; accepted 26 May 2013

Copyright (C) 2013 Adrienne M. Gilligan et al. This is an open access article distributed under the Creative Commons Attribution License, which permits unrestricted use, distribution, and reproduction in any medium, provided the original work is properly cited.

\section{ABSTRACT}

Objectives: Determine predictors of hospitalization and institutionalization in Medicaid populations with Alzheimer's Disease (AD). Methods: Data were obtained from the Centers for Medicare and Medicaid Services (CMS). Individuals enrolled in Florida, New Jersey, and New York Medicaid programs on January 1, 2004, remained in that program for 1 year and exposed to an AD medication were included. AD diagnosis was based on the ICD-9-CM code 331.0. Outcomes of interest were hospitalization and institutionalization. Multivariate logistic regression models were used to test for the association between outcomes of interest and demographics, resource utilization factors, and type of AD pharmacotherapy exposure. Results: A total of 65,442 individuals qualified for the study. Age was positively and significantly associated with hospitalization $(p<0.001)$ and institutionalization $(p<0.001)$. Exposure to memantine was significantly associated with less chance of hospitalization (OR $=0.88 ; 99 \% \mathrm{Cl}$ : $0.77-0.99)$. Non-Hispanic Blacks were significantly $(p<$ $0.001)$ more likely to be hospitalized than Non-Hispanic Whites (OR $=1.60 ; 99 \% \mathrm{Cl}$ : 1.41 1.81). Compared to Non-Hispanic Whites, Non-Hispanic Blacks (OR $=0.73$; $99 \% \mathrm{Cl}$ : 0.60 0.88 ), Hispanics (OR $=0.36 ; 99 \% \mathrm{Cl}: 0.27-0.47$ ), and Non-Hispanic Others (OR $=0.42 ; 99 \% \mathrm{Cl}$ : $0.21-0.82$ ) were significantly less likely to be institutionalized. Individuals prescribed donepezil (OR $=1.29,99 \% \mathrm{Cl}, 1.08-1.54)$ and galantamine (OR = 1.46, 99\% Cl: 1.19 - 1.79) were significantly more likely to have an institutionalization claim ( $p<0.001$ for both medications).
Residents of New York were significantly more likely to be hospitalized than Florida residents (OR = 1.30; 99\% Cl: 1.17 - 1.44), whereas New Jersey residents were significantly less likely to be hospitalized (OR $=0.75 ; 99 \% \mathrm{Cl}$ : $0.66-0.85)$. Finally, compared to Florida residents, residents of New Jersey were significantly more likely to be institutionalized (OR $=4.61 ; 99 \% \mathrm{Cl}$ : 3.98 5.33). Conclusion: Demographics, state of residence and pharmacotherapy exposure were significant predictors of health care service utilization. Further pharmacoeconomic studies in AD medication therapy are warranted.

Keywords: Alzheimer's Disease; Cost; Medicaid; Pharmacotherapy

\section{INTRODUCTION}

There are approximately 34.3 million individuals worldwide, and as many as 5.3 million Americans who are living with Alzheimer's Disease (AD) [1]. Currently, AD is the sixth-leading cause of death in the United States and the fifth leading cause of death among those 65 and older worldwide [1]. By 2050, approximately 16 million Americans may have $\mathrm{AD}$ [2].

The worldwide economic burden of Alzheimer's is substantial, as the annual global societal costs of $\mathrm{AD}$ were estimated to be approximately $\$ 422$ billion (U.S. dollars) in 2009. In the US, payers such as Medicare and Medicaid cover about $70 \%$ of the costs of care. Aggregate payments for health care, long-term care and hospice for individuals with Alzheimer's are projected to increase from \$200 billion in 2012 to $\$ 1.1$ trillion in 2015 [1]. It has been shown that a Medicare beneficiary with $\mathrm{AD}$ cost approximately three times more than those without $\mathrm{AD}$ ( $\$ 43,847$ versus $\$ 13,879$, respectively) [1]. 
The majority of these costs are attributed to annual nursing home care (\$17,693 versus $\$ 786$, respectively) expenses and inpatient hospitalization costs (\$9732 versus \$3912, respectively) [1].

In addition to direct payments related to AD, substantial indirect nonmedical costs also exist. Over 15 million Americans provide unpaid care for a person with Alzheimer's. Family members provide approximately 80\% of informal care [1]. In 2011, unpaid caregivers provided an estimated 17.4 billion hours of unpaid care, a contribution valued at over $\$ 210$ billion [1].

Approximately $70 \%$ of the more than 5 million Americans with AD will be cared for in nursing homes during the final stage of their illness [1]. In the US, the federal Medicaid program covers nursing home care and other long-term care services in the community for individuals who meet program requirements for level of care, income and assets. The majority of nursing home residents who qualify for Medicaid must spend nearly all of their Social Security income and other monthly income to pay for nursing home care. Currently, approximately 58\% of Medicaid spending is allocated to long-term care. Total Medicaid spending for people with AD is projected to be $\$ 35.5$ billion in 2012 [3]. About half of all Medicaid beneficiaries with $\mathrm{AD}$ are nursing home residents. Among nursing home residents with AD, approximately 51\% rely on Medicaid to help pay for their long-term care [4].

Treatment of AD involves both pharmacologic and non-pharmacologic treatments. The Food and Drug Administration (FDA) has approved two symptomatic treatment approaches for the treatment of AD: the inhibition of acetylcholinesterase (using cholinesterase inhibitors (ChEIS) such as donepezil, galantamine, and rivastigmine) and the inhibition of N-methyl-D-aspartate (NMDA) receptors (using memantine). The main focus of drug treatment for $\mathrm{AD}$ is to improve cognitive function, such as memory and thinking, and to slow the progression of symptoms. Most evidences relating to pharmacological treatments of AD (e.g. donepezil, galantamine, rivastigmine, tacrine and memantine) have demonstrated statistically significant improvements in clinicians' and caregivers' global assessments and in slowing the rate of decline in cognition [5-9]. ChEIs have also been approved, as they show positive effects on cognition and activities of daily living (ADL) in AD patients [10]. In addition, memantine can provide symptomatic improvement in several different patient-relevant domains [10].

Due to the significant financial burden of $\mathrm{AD}$ from both payers and societal perspective, an increasing interest exists in assessing predictors in health care delivery in patients with AD. Regardless of the clinical and technological innovations, limitations remain in the quality of health care in the US [11-13]. Therefore, the purpose of this study was to analyze predictors of hospitali- zation and institutionalization in Medicaid populations for patients with AD while controlling for demographics, resource utilization, and type of $\mathrm{AD}$ pharmacotherapy exposure.

\section{METHODS}

\subsection{Claims Files}

This research was an observational retrospective study using Medicaid and Medicare administrative data from Florida, New Jersey, and New York. The data were extracted from the Medicaid Analytic Extract File (MAX) from the Centers for Medicare and Medicaid services. MAX files are person-level data on Medicaid eligibility, service utilization and payment information for all individuals. MAX consists of a Personal Summary File and four encounter/service claim files, which include: inpatient; long-term care; other services (i.e., outpatient); and prescription medications. Due to the high likelihood for dual Medicaid/Medicare eligibility, institutional, outpatient, and beneficiary summary files from Medicare (MedPAR) were used to capture additional health expenditures among subjects. Dual eligible are individuals who are entitled to Medicare Part A and/or Part B and are eligible for some form of Medicaid. The primary outcomes of interest were hospitalization and institutionalization for AD patients during the one-year time period. Outcomes were derived from the inpatient and long-term care claims from the MAX dataset. Hospitalization was derived from at least 1 stay in an inpatient care facility (scored as a dichotomous variable) and institutionalization from at least 1 stay in a long-term care facility (scored as a dichotomous variable). AD medication use for identifying cholinesterase inhibitor (ChEI) or memantine was based on national drug codes (NDCs).

Inpatient claims files include a total of 10 diagnosis sections, long-term care contains 5 diagnosis sections, and outpatient includes 2 sections. AD was identified based on the International and Statistical Classification of Diseases and Related Health Problems Version 9 (ICD-9) code 331.0. This is the only ICD-9 code that provides a diagnosis for AD. If patients had a diagnosis of 331.0 in any section of the inpatient, long-term care or outpatient claim files Medicaid claim files, then they were considered to have an $\mathrm{AD}$ diagnosis.

\subsection{Inclusion/Exclusion Criteria}

To be eligible for this study, persons with AD had to be enrolled in a Florida, New Jersey, or New York Medicaid program on January 1, 2004 and remain in that Medicaid program through December 31, 2004. These states were selected due to large populations and had the fewest prescription restrictions for Medicaid beneficiaries (i.e., quantity supplied allowed per month and cost of 
medications). This particular date range was selected due to the completeness of the ethnicity data in the MAX dataset and because Medicare Part D was not yet implemented. Further inclusion criteria included being exposed to only one $\mathrm{AD}$ drug during this time period in order to assess the impact of individual AD medications on cost of care. Patients who were exposed to only one AD medication had to have one pharmacy claim for a cholinesterase inhibitor (ChEI) or memantine to be included, regardless if treatment was continued throughout the year. All cholinesterase inhibitors and memantine were available during 2004. Memantine was the last drug to be approved by the FDA in 2003. However, there were no generic versions of these mediations available during 2004.

Since this study was specifically interested in AD disease, patients with an ICD-9 code relating to dementia other than AD, which include all 290 codes (senile dementia), 291.2 (other alcoholic dementia), 292.82 (druginduced dementia), 294.10 - 294.11 (dementia in condition classified elsewhere), 294.8 (dialysis dementia), 295.0 - 298.8, 293.0 - 293.9, 310.10, 331.1 (Pick’s disease), 331.2 (senile degeneration), and 797 (senile) were excluded. Age was restricted from 50 to 99 years. Individuals under 50 and over 99 were excluded to prevent the possibility of identification due to limited sample size (i.e., less than 10 patients). Those who were had no prescription medication claims or had greater than or equal to 2 different $\mathrm{AD}$ drug claims were excluded.

\subsection{Statistical Analyses}

Independent variables of interest included demographic characteristics, resource utilization, and pharmacotherapy. Patient co-morbidities were identified through the ICD$9-\mathrm{CM}$ procedure code provided in the MAX medical claims data. Independent variables for predictors of hospitalization and institutionalization included: race; age; Charlson co-morbidity score [14]; state (each scored as a categorical variable with Florida as the referent group); gender; and type of $\mathrm{AD}$ medication prescribed during the year (i.e., donepezil, galantamine, rivastigmine, or memantine). Non-Hispanic White was the referent group for race. In the MAX database, race and ethnicity are combined under one variable. Non-Hispanic other individuals were identified as those who affiliated with any of the following: "Alaskan Native," "Asian or Pacific Islander," or "Native Hawaiian or Other Pacific Islander" and not of Hispanic origin.

The Charlson Comorbidity Index (CCI) measures the risk of one-year mortality for longitudinal studies for 22 co-morbid conditions [15]. Assigned weights for each condition can equal 1, 2, 3, or 6 depending on severity. Because this index was not designed for retrospective studies, this study used an enhanced ICD-9 modification which links the comorbid conditions to ICD-9 codes in administrative databases. The enhanced ICD-9 modification adjusts the amount of comorbid conditions to 17 . The enhanced ICD-9 coding algorithm was selected for this study because it has demonstrated better performance in calculating comorbidities compared to the Deyo/ Elixhauser algorithms [14]. Dementia was removed from the comorbidity calculation in order to avoid overestimating the mean score.

Descriptive analyses included statistics of frequencies, percentages, and means for all variables. Total cost of care was reported as a descriptive statistic. Total cost of care consisted of costs derived from the inpatient, longterm care, outpatient, and prescription claims from the MAX dataset in addition to costs derived from the MedPAR institutional, outpatient and beneficiary summary claims that were not covered by either provider. A one-way analysis of variance (ANOVA) was calculated to test for statistically significant differences in cost of care across states. Tukey's range test was used post-hoc to assess costs across states that were significantly different from each other. Chi-square analysis was conducted in order to determine if type of unique AD medication exposed to differed significantly depending on state.

Multivariate logistic regression was used to test for the association between hospitalization and institutionalization when demographic characteristics (e.g., sex, age, race, state of residence, Charlson comorbidity index), exposure to unique $\mathrm{AD}$ pharmacotherapy medications, and resource utilization were included in the model. All statistical analyses were conducted in SAS version 9.2 for Windows 7 and Intercooled STATA 11.0 for Windows 7. An alpha $(\alpha)$ level of 0.01 was selected a-priori for all analyses due to the large sample size.

\section{RESULTS}

Excluding non-AD patients, there were a total of 105,961 subjects. When applying the inclusion criteria of being exposed to only one type of AD pharmacotherapy in 2004, a total of 65,442 (61.8\%) individuals were identified for inclusion, with all persons being eligible for both Medicare and Medicaid. This indicates that the majority of individuals in 2004 on AD medications were only exposed to one medication.

Demographics for AD Medicaid patients $(n=65,442)$ are displayed in Table 1. The majority of observations across all states were females (greater than $70 \%$ ). The average age ranged from 76 to 80 years. Charlson scores ranged from 3.2 to 3.4 across all states ( $\mathrm{SD}=2.7$ to 2.9 ). The state with largest proportion of Medicaid observations was Florida (approximately 46.4\%), followed by New York (approximately 32.6\%) and 21.0\% resided in New Jersey. Hispanics had the highest frequency of individuals in Florida (approximately 26.8\%). 
Table 1. Demographics for Medicaid Patients with Alzheimer's Disease in Florida, New Jersey, and New York $(\mathrm{n}=65,442)$.

\begin{tabular}{|c|c|c|c|c|c|c|c|}
\hline State & $\begin{array}{l}\text { Race } \\
\text { N (\%) }\end{array}$ & $\begin{array}{l}\text { Gender } \\
\text { (\% female) }\end{array}$ & $\begin{array}{c}\text { Age } \\
\text { Mean (SD) }\end{array}$ & $\begin{array}{l}\text { Charlson Score } \\
\text { Mean (SD) }\end{array}$ & $\begin{array}{c}\text { Inpatient (Y/N) } \\
\mathrm{N}(\%)\end{array}$ & $\begin{array}{c}\text { Long-Term Care (Y/N) } \\
\text { N (\%) }\end{array}$ & $\begin{array}{c}\text { Total Cost of Care } \\
\text { Mean (SD) }\end{array}$ \\
\hline $\begin{array}{c}\text { Florida } \\
(\mathrm{n}=30,233)\end{array}$ & $\begin{array}{lrr}\text { White: } & 15,408(51.0) \\
\text { Black: } & 3430(11.4) \\
\text { Hispanic: } & 8091(26.8) \\
\text { Other: } & 139(0.5)\end{array}$ & 72.2 & $78.6(9.7)$ & $3.2(2.7)$ & 1676 (46.1) & $497(26.0)$ & $\begin{array}{l}\$ 1861.81^{\mathrm{a}} \\
(9347.21)\end{array}$ \\
\hline $\begin{array}{l}\text { New Jersey } \\
(\mathrm{n}=13,880)\end{array}$ & $\begin{array}{lr}\text { White: } & 8682(62.3) \\
\text { Black: } & 2000(14.4) \\
\text { Hispanic: } & 1030(7.4) \\
\text { Other: } & 126(0.9)\end{array}$ & 75.1 & 79.9 (9.6) & $3.4(2.8)$ & 615 (16.9) & 1112 (58.2) & $\begin{array}{l}\$ 2810.23^{b} \\
(13117.86)\end{array}$ \\
\hline $\begin{array}{l}\text { New York } \\
(\mathrm{n}=21,329)\end{array}$ & $\begin{array}{lr}\text { White: } & 11,833(55.5) \\
\text { Black: } & 2347(11.0) \\
\text { Hispanic: } & 1091(5.1) \\
\text { Other: } & 1182(5.5)\end{array}$ & 71.7 & 75.7 (10.3) & $3.2(2.9)$ & $1346(37.0)$ & 302 (15.8) & $\begin{array}{l}\$ 1087.18^{\mathrm{c}} \\
(10582.00)\end{array}$ \\
\hline
\end{tabular}

${ }^{\mathrm{a}}$ : Cost of care significantly different from Florida and New Jersey $(\mathrm{p}<0.01) ;{ }^{\mathrm{b}}$ : Cost of care significantly different from Florida and New York (p < 0.01); ${ }^{\mathrm{c}}$ : Cost of care significantly different from New Jersey and New York $(\mathrm{p}<0.01)$.

New Jersey had the highest frequency of individuals for Non-Hispanic whites and Non-Hispanic blacks (62.3\% and $14.4 \%$, respectively). Non-Hispanic others had the highest frequency of individuals in New York (approximately 5.5\%). New Jersey had the highest annual total cost of care per individual (approximately \$2810.23, SD $=\$ 13117.86$ ), while New York had the lowest annual cost of care (approximately \$1087.18, SD = \$10582.00). Total cost of care significantly differed between states (p $<0.0001$ ).

There were a total of 3637 individuals who were hospitalized (approximately $5.6 \%$ of the sample). The majority of these claims were from Florida and New York (46.1\% and 37.0\%, respectively). Only a total of 1911 (approximately $2.9 \%$ ) of individuals in this sample had a long-term care claim in 2004. The majority of these claims were from those in New Jersey and Florida (58.2\% and $26.0 \%$, respectively).

The proportion of AD medication type stratified by state is displayed in Table 2. Donepezil was the most common AD medication across all states (61.9\% for Florida residents, $68.9 \%$ for residents of New Jersey, and $67.0 \%$ for New York residents). Exposure to galantamine was the second most frequent medication for residents of Florida and New Jersey (16.4\% and 12.7\%, respectively). For individuals residing in New York, memantine was the second most frequent medication prescribed (approximately $16.2 \%$ ). Rivastigmine was the least frequent medication prescribed in Florida and New Jersey (6.3\% and 7.3\%, respectively).

Adjusting for demographics and pharmacotherapy exposure (Table 3), having one or more hospitalizations increased as age increased $(\mathrm{OR}=1.04$; 99\% CI, 1.03 1.05). Non-Hispanic blacks were significantly more likely $(\mathrm{OR}=1.60 ; 99 \% \mathrm{CI}, 1.41$ - 1.81) to be hospitalized than Non-Hispanic whites ( $\mathrm{p}<0.001)$. Compared to residents in Florida, individuals residing in New Jersey were sig- nificantly less likely $(\mathrm{OR}=0.75 ; 99 \% \mathrm{CI}, 0.66$ - 0.85) to be hospitalized ( $\mathrm{<}<0.001$ ); however, New York residents were significantly more likely (OR $=1.30$; 99\% CI, 1.17 - 1.44) to be hospitalized ( $<<0.001$ ) than individuals in Florida. Exposure to memantine was significantly associated ( $\mathrm{p}=0.01$ ) with less chance of hospitalization (OR = 0.88; 99\% CI, 0.77 - 0.99).

One or more claims for long-term care institutionalization increased as age increased (OR $=1.03$; 99\% CI, 1.02 - 1.04). Non-Hispanic blacks (OR $=0.73,99 \% \mathrm{CI}$, 0.60 - 0.88), Hispanics (OR = 0.36, 99\% CI, 0.27 - 0.47), and Non-Hispanic others (OR $=0.42,99 \% \mathrm{CI}, 0.21$ 0.82 ) were significantly less likely to have a claim for long-term care compared to Non-Hispanic whites ( $\mathrm{p}<$ $0.0001,<0.0001$, and 0.001 , respectively). Residents of New Jersey were significantly more likely $(\mathrm{OR}=4.61$, $99 \%$ CI, 3.98 - 5.33) to have a long-term care claim compared to individuals residing in Florida ( $\mathrm{p}<0.0001)$. No significant differences for long-term care claims were found between Florida and New York. Individuals prescribed donepezil (OR = 1.29, 99\% CI, 1.08 - 1.54) and galantamine $(\mathrm{OR}=1.46$, 99\% CI, 1.19 - 1.79) were significantly more likely to have an institutionalization claims compared to those who did not ( $p<0.001$ for both medications).

\section{DISCUSSION}

AD not only affects patients, but also affects family and loved ones physically, financially, and emotionally. Identifying potential predictors of hospitalization and institutionalization in patients with AD may help states implement cost-saving policies, and provide states with the financial ability to treat more AD Medicaid patients.

Demographic characteristics and state of residence was attributed to health care service utilization. Age, NonHispanic black race/ethnicity, and residing in New York 
Table 2. Proportion of Alzheimer's Disease Medication use Stratified by State.

\begin{tabular}{cccccc}
\hline & Donepezil N (\%) & Galantamine N (\%) & Rivastigmine N (\%) & Memantine N (\%) & Total $^{*}$ N (\%) \\
\hline Florida & $18,707(61.9)$ & $4966(16.4)$ & $1902(6.3)$ & $4658(15.4)$ & $30,233(46.2)$ \\
New Jersey & $9558(68.9)$ & $1769(12.7)$ & $1010(7.3)$ & $1543(11.1)$ & $13,880(21.2)$ \\
New York & $14,293(67.0)$ & $1466(6.9)$ & $2108(9.9)$ & $3462(16.2)$ & $21,329(32.6)$ \\
\hline
\end{tabular}

*: Chi-square results: statistically significant differences between type of unique AD medication exposed to and state (p < 0.01 ).

Table 3. Association of Demographic Factors and Unique Alzheimer's Disease Pharmacotherapy Exposure with Health Care Service Utilization $(n=65,442)$.

\begin{tabular}{|c|c|c|c|c|c|c|}
\hline \multirow[b]{2}{*}{ Full Model } & \multicolumn{3}{|c|}{ Inpatient Hospitalization } & \multicolumn{3}{|c|}{ Long-Term Care Institutionalization } \\
\hline & OR $(99 \%$ CI) & SE & p-value & OR $(99 \% \mathrm{CI})$ & SE & p-value \\
\hline Age & $1.04(1.03,1.05)$ & 0.01 & $<0.001$ & $1.03(1.02,1.04)$ & 0.01 & $<0.001$ \\
\hline Gender & $1.08(0.97,1.19)$ & 0.04 & 0.07 & $1.02(0.89,1.19)$ & 0.06 & 0.65 \\
\hline Charlson Score & $1.00(0.99,1.02)$ & 0.01 & 0.75 & $1.01(0.99,1.04)$ & 0.01 & 0.10 \\
\hline \multicolumn{7}{|l|}{ Race } \\
\hline Black & $1.60(1.41,1.81)$ & 0.08 & $<0.001$ & $0.73(0.60,0.88)$ & 0.05 & $<0.001$ \\
\hline Hispanic & $1.11(0.96,1.27)$ & 0.06 & 0.06 & $0.36(0.27,0.47)$ & 0.04 & $<0.001$ \\
\hline Other & $1.13(0.84,1.52)$ & 0.13 & 0.28 & $0.42(0.21,0.82)$ & 0.11 & 0.001 \\
\hline \multicolumn{7}{|l|}{ State } \\
\hline Florida & Reference & & & Reference & & \\
\hline New York & $1.30(1.17,1.44)$ & 0.05 & $<0.001$ & $0.95(0.78,1.16)$ & 0.07 & 0.50 \\
\hline \multicolumn{7}{|c|}{ AD Medication Type } \\
\hline Donepezil & Reference & & & Reference & & \\
\hline Galantamine & $0.94(0.81,1.08)$ & 0.05 & 0.23 & $1.29(1.08,1.54)$ & 0.08 & $<0.001$ \\
\hline Rivastigmine & $0.93(0.78,1.10)$ & 0.06 & 0.27 & $1.46(1.19,1.79)$ & 0.12 & $<0.001$ \\
\hline Memantine & $0.88(0.77,0.99)$ & 0.05 & 0.01 & $1.04(0.85,1.26)$ & 0.08 & 0.65 \\
\hline
\end{tabular}

had significant and positive associations with hospitalization, while residing in New Jersey and having exposure to memantine were associated with a decrease in the odds of being hospitalized. Age, residing in New Jersey, and having exposure to donepezil and galantamine were associated with increased odds of residing in a long-term care facility. These results are consistent with those reported by Yang et al., who found that age, gender, race, education, chronic conditions, and geographic location were significant predictors of Medicaid expenditures among persons with AD [16]. Results from this study are comparable to the overall $\mathrm{AD}$ population. Currently, the majority of patients in the overall $\mathrm{AD}$ population are over 75 years old (90\%), with $65 \%$ being female [1]. Prevalence rates are anticipated to increase between $49 \%$ - 81\% in Florida and 0\% - 24\% in New Jersey and New York [1].

All race/ethnic groups (e.g., Non-Hispanic black, Hispanic, and Non-Hispanic other) were associated with decreased association of institutionalization. Research consistently shows that non-Hispanic blacks, Hispanics, and persons with ethnicity classified as other, caregivers were less likely than non-Hispanic whites to place their relative with $\mathrm{AD}$ in long-term care [17]. A potential reason for these racial/ethnic differences is caregiver coping style or amount of involvement in care giving [18]. Minorities have less access to long-term care facilities, have different family structures, and have different attitudes toward institutionalization [19]. Determining the underlying factors behind these reasons for placement of patients with $\mathrm{AD}$ in long-term care remains an important question for future research when examining total cost of care and health disparities.

Approximately $29 \%$ of older individuals with AD who have Medicare also have Medicaid coverage, compared with the $11 \%$ of individuals without Alzheimer's [10]. In 2008, average Medicaid payments per person for Medicare beneficiaries age 65 and older with AD were 19 times as great as average Medicaid payments for Medicare beneficiaries without $\mathrm{AD}(\$ 10,120$ per person for individuals with $\mathrm{AD}$ compared with $\$ 527$ for individuals without AD) [10]. Much of the difference in these costs is associated with long-term care (i.e., nursing homes and assisted living facilities). Medicaid paid \$23,953 per 
person for Medicare beneficiaries with Alzheimer's living in a long-term care facility compared with \$222 for community-dwellers nationwide [10].

State of residence was a significant factor in predicting health care utilization, particularly for patients who were hospitalized. In 2004, New Jersey spent $\$ 8$ billion on its Medicaid program, roughly half of which was not financed through the state [20]. New Jersey spent approximately $\$ 5437$ per Medicaid enrollee, $10^{\text {th }}$ highest among states, while the national average per enrollee was \$4011 [20]. Furthermore, beneficiary access to Medicaid benefits came primarily through hospitals and outpatient clinics, rather than office-based physicians. During 2004 the state spent $1.8 \%$ of its acute care Medicaid bill on physician/lab/x-ray services, compared to the $6.7 \%$ national average [21]. In addition, New Jersey spent $16.7 \%$ on outpatient clinic services, as opposed to the national average of $11.5 \%$ [21]. The main reason for this was attributed to New Jersey paying unusually low reimbursement rates to physicians, paying only 56\% of the national average physician reimbursement level [21].

Hospital inpatient services are Medicaid's single largest expenditure, and are even more expensive for $\mathrm{AD}$ patients; however, wide variation exists across states regarding payment methods. For inpatient services, costbased reimbursement and per diem reimbursement have perverse incentives that encourage more care and less efficiency; yet, more than a dozen states use one of these methods (e.g., Florida uses per diem reimbursement) [22]. In addition, Medicaid fee-for-service methods and levels influence access, quality, and costs and are central components of payment innovations. In 2007, New York's physician fee schedule was the second lowest in the country [23]. Furthermore, the inpatient payment methodology was similarly flawed and Medicaid inpatient rates actually exceeded Medicaid inpatient costs, incentivizing expensive inpatient care and contributing to New York's last place ranking in a 50-state survey of avoidable hospital admissions [23]. Recently, New York has switched to an All Patient Refined Diagnostic Related Group (APRDRG) to help with cost containment [22].

Medicaid plays an essential role in financing longterm care. About 35\% of Medicaid spending in 2004 was for long-term care [24]. However, there was tremendous variation in state coverage and spending. Results from this study demonstrated that, for those with a long-term care claim, individuals residing in New Jersey were almost five times more likely to be institutionalized. New Jersey spends almost $40 \%$ of its Medicaid dollars on long-term care [25]. Multiple factors can be contributed to differences in state Medicaid spending, including: coverage and reimbursement policies, participation rates (i.e. the proportion of eligible residents who are actually enrolled in Medicaid), and waiver programs offered by each state. A study conducted by Fossett and Burke (2010) calculated a long-term care population and service generosity scored based upon the following services: home health, hospice, personal care, private duty nurse, intermediate care, inpatient psychiatric care, and nursing home to rank each state [26]. Results demonstrated that New Jersey was ranked among the least generous state as measured by this standard, while New York was the most generous [26]. One possible method for addressing longterm care policy in Medicaid is to assess comparative studies of groups of states (i.e., cluster analyses) to assess similarities and differences in long-term care spending patterns and utilization. In addition, Medicaid waivers for home and community based programs are available in several states; future research should be conducted to assess if cost-savings benefits can occur in states with substantial Medicaid expenses (i.e., New Jersey and Florida).

Limited research exists on the cost-effectiveness of AD pharmacotherapy; however, studies that have been conducted have demonstrated cost-savings when exposed to AD medications [8,27]. Gilligan et al. analyzed cost of care in Medicaid patient populations and found that among individuals who received 1 unique $\mathrm{AD}$ medication, total health care expenditures decreased significantly compared to those receiving no pharmacotherapy ( $\mathrm{p}<0.001$ ); however, when level of exposure increased to 2 or more drugs, there was no difference in cost between individuals who received medication therapy as compared to those who received none [28]. A systematic review conducted by Cappell et al. examining pharmacoeconomic studies of these medications also suggests that cost of care is lower when AD patients receive pharmacotherapy [27]. Memantine is a medication that is indicated for moderate-to-severe stages of $\mathrm{AD}$; therefore a potential reason why the costs of care are significantly higher in long-term care populations is most likely due to higher costs associated with later stages of $\mathrm{AD}$ rather than the medication itself.

Not surprisingly, those exposed to memantine were significantly less likely to be hospitalized, further evidence that less severe patients may be receiving the medication. A potential reason for this could be that those in later stages of AD forgo hospitalization in lieu of home care or care provided at the nursing home. Research suggests that certain common acute conditions, such as pneumonia, can be treated with the same efficacy and at reduced costs in the nursing home than in the hospital [29,30]. The potential benefits of hospitalization may outweigh its burdens for patient's whose primary goal of care remains life prolongation, but comfort if often considered the priority of care in the final stages of AD [31]. Prior research indicates that these patients often undergo distressing interventions in the hospital that may 
be of limited benefit [32]. Therefore, hospital transfer is seldom consistent with a palliative approach except when the treatment needed to promote comfort cannot be provided in home care or the nursing home.

Individuals who were exposed to donepezil and galantamine were significantly more likely to be institutionalized than individuals who were not. These results differ from those found in previous studies. Studies have evaluated the predictors of nursing home placement (NHP), while focusing on the effects of cholinesterase inhibitor use on NHP [33]. Two studies conducted in the U.S. found an inverse relationship between ChEI exposure and NHP; one study found that treatment decreased the risk of NHP [34], and the second study found that treatment with tacrine at doses greater than $80 \mathrm{mg} / \mathrm{d}$ was associated with a reduced likelihood of NHP [35]. Beusterien et al. found that after controlling for known predictors of NHP such as age, number of co-morbidities and behaveioral disturbances, control participants were almost 3-fold as likely to be admitted to a nursing home than those taking rivastigmine [33]. Further pharmacoeconomic studies in $\mathrm{AD}$ medication therapy are warranted.

\subsection{Limitations}

Several limitations exist within this study. First, while this study used the Charlson co-morbidity index to measure disease burden, there were no data elements present to evaluate the severity of AD. Differences observed may reflect duration of disease and/or severity of disease. These factors cannot be easily controlled for using administrative data. In addition, persons who received medication therapy may have unobserved characteristics that contribute to the use of AD-related medications for other conditions (i.e., Parkinson's disease). The majority of diagnoses of Alzheimer's came from outpatient claim files; while this is not necessarily a limitation, this should be considered when interpreting these results.

An additional limitation is the timeline of the study. This study only observed individuals during the year 2004 because of significant changes in the proportion of individuals who had missing race information in 2005. The one-year limitation inhibits determining long-term costs, assessing costs at different stages of the disease, and changes to Medicaid eligibility status (i.e., was the patient continuously on Medicaid or did they rotate on and off during subsequent years). Since this analysis was based on cross-sectional data, causal inferences cannot be made. When examining long-term care claims, it was unable to be determined if a patient had a confirmatory claim throughout the study timeframe (i.e., whether or not the patient resided solely in a facility throughout the year). In addition, since state Medicaid policies change annually, a one-year time period was deemed appropriate to avoid reimbursement and eligibility concerns. Furthermore, this study evaluated medication use before 2006, when Medicare Part D was implemented. Until recently, it was not possible to track medication use among individuals in both Medicaid and Medicare programs and prescription drug use. Because of the short time frame for this study, future evaluations should observe total cost of care over multiple years since $\mathrm{AD}$ is a chronic progressive condition. Gaps in clinical information and the billing context often compromise the ability to create valid appraisals from administrative data.

Numerous unobservable determinants (i.e., variables not used in the above models) may play a role in cost of care, whether it's care-seeking behavior, selection-criteria into Medicaid programs, treatment of Medicaid enrollees, or physician practice styles.

\subsection{Conclusions}

Demographic characteristics, state of residence and pharmacotherapy exposure were significant predictors of health care service utilization. Predictors of hospitalizetion included age, Non-Hispanic black race/ethnicity, and residing in New York. Exposure to memantine was negatively associated with the odds hospitalization. Predictors of institutionalization were age and residing in New Jersey. Exposure to donepezil or galantamine was positively and significantly associated with institutionalization. Furthermore, geographical location proved to be a significant predictor of health care service utilization.

As the cost of care increasing for $\mathrm{AD}$ and other Medicaid patients, policymakers nationwide need to simultaneously expand access to public insurance coverage and contain the costs of that coverage. Medicaid long-term care policy that analyzes potential clustering of states will be useful in cost containment, especially in AD patient populations, since they comprise a significant portion of long-term care utilization and expenses.

\section{REFERENCES}

[1] Alzheimer's Association (2012) Alzheimer's disease facts and figures. Alzheimer's \& Dementia: The Journal of the Alzheimer's Association, 7, 1-72.

[2] Hebert, L.E., Scherr, P.A., Bienias, J.L., Bennett, D.A. and Evans, D.A. (2003) Alzheimer disease in the US population: Prevalence estimates using the 2000 census. Archives of Neurology, 60, 1119-1122.

doi:10.1001/archneur.60.8.1119

[3] The Lewin Group (2010) Lewin Model on Alzheimer's and dementia and costs. The model estimates total payments for community-based health care services using data from the Medicare Current Beneficiary Survey (MCBS). www.alz.org/trajectory. 
[4] Bynum, J. and Dartmouth, M.P.H. (2008) Medicare current beneficiary survey. Institute for Health Policy and Clinical Care, Dartmouth Medical School.

[5] Areosa Sastre, A., McShane, R. and Sherriff, F. (2004) Memantine for dementia. Cochrane Database of Systematic Reviews, 4, CD003154.

[6] Birks, J., Grimley, E. J., Iakovidou, V., Tsolaki, M. and Holt, F.E. (2009) Rivastigmine for Alzheimer's disease. Cochrane Database of Systematic Reviews, 2, CD001191.

[7] Birks, J.S. and Harvey, R. (2003) Donepezil for dementia due to Alzheimer's disease. Cochrane Database of Systematic Reviews, 3, CD001190.

[8] Qizilbash, N., Whitehead, A., Higgins, J., Wilcock, G., Schneider, L. and Farlow, M. (1998) Cholinesterase inhibition for Alzheimer disease: A meta-analysis of the tacrine trials. Dementia trialists' collaboration. Journal of the American Medical Association, 280, 1777-1782. doi:10.1001/jama.280.20.1777

[9] Loy, C. and Schneider, L. (2004) Galantamine for Alzheimer's disease. Cochrane Database of Systematic Reviews, 4, CD001747.

[10] Pouryamout, L., Dams, J., Wasem, J., Dodel, R. and Neumann, A. (2012) Economic evaluation of treatment options in patients with Alzheimer's disease: A systematic review of cost-effectiveness analyses. Drugs, 72, 789802. doi:10.2165/11631830-000000000-00000

[11] Institute of Medicine (2001) Crossing the quality chasm: A new health system for the 21st century. National Academy Press, Washington DC.

[12] Jencks, S.F., Cuerdon, T., Burwen, D.R., Fleming, B., Houck, P.M., Kussmaul, A.E., et al. (2000) Quality of medical care delivered to medicare beneficiaries: A profile at state and national levels. Journal of the American Medical Association, 284, 1670-1676. doi:10.1001/jama.284.13.1670

[13] McGlynn, E.A., Asch, S.M., Adams, J., Keesey, J., Hicks, J., DeCristofaro, A., et al. (2003) The quality of health care delivered to adults in the United States. The New England Journal of Medicine, 348, 2635-2645. doi:10.1056/NEJMsa022615

[14] Quan, H., Sundararajan, V., Halfon, P., Fong, A., Burnand, B., Luthi, J.C., et al. (2005) Coding algorithms for defining comorbidities in ICD-9-CM and ICD-10 administrative data. Medical Care, 43, 1130-1139. doi:10.1097/01.mlr.0000182534.19832.83

[15] Charlson, M.E., Pompei, P., Ales, K.L. and MacKenzie, C.R. (1987) A new method of classifying prognostic comorbidity in longitudinal studies: Development and validation. Journal of Chronic Diseases, 40, 373-383. doi:10.1016/0021-9681(87)90171-8

[16] Yang, Z., Zhang, K., Lin, P.J., Clevenger, C. and Atherly, A.A. (2012) Longitudinal analysis of the lifetime cost of dementia. Health Services Research; 47(4): 1660-1678. doi:10.1111/j.1475-6773.2011.01365.x

[17] Schulz, R., Belle, S.H., Czaja, S.J., McGinnis, K.A., Stevens, A. and Zhang, S. (2004) Long-term care placement of dementia patients and caregiver health and well-being. Journal of the American Medical Association, 292, 961-

\section{7. doi:10.1001/jama.292.8.961}

[18] McClendon, M.J., Smyth, K.A. and Neundorfer, M.M. (2006) Long-term-care placement and survival of persons with Alzheimer's disease. Journals of Gerontology Series B: Psychological Sciences and Social Sciences, 61, P220P227. doi:10.1093/geronb/61.4.P220

[19] Haley, W.E., Gitlin, L.N., Wisniewski, S.R., Mahoney, D.F., Coon, D.W., Winter, L., et al. (2004) Well-being, appraisal, and coping in African-American and Caucasian dementia caregivers: Findings from the REACH study. Aging \& Mental Health, 8, 316-329. doi:10.1080/13607860410001728998

[20] Kaiser Family Foundation (2005) State Health Facts. http://www.statehealthfacts.kff.org

[21] The Robert Wood Johnson Foundation (2005) Changes in Medicaid physician fees, 1998-2003: Implications for physician participation. http://www.rwjf.org/newsroom/featureDetail.jsp?featureI $\mathrm{D}=550$ \&pageNum $=1$ \&type $=3$

[22] Bachrach, D. (2010) Payment reform: Creating a sustainable future for Medicaid. Center for Health Care Strategies, Inc., 1-14.

[23] McCarthy, D. (2009) Aiming higher: Results from a state scorecard on health system performance. The Commonwealth Fund.

[24] O’Brien, E. (2005) Long-term care: Understanding Medicaid's role for the elderly and disabled. The Kaiser Commission on Medicaid and the Uninsured.

http://kaiserfamilyfoundation.files.wordpress.com/2013/0 1/long-term-care-understanding-medicaid-s-role-for-the-e lderly-and-disabled-report.pdf

[25] Sparer, M., Glied, S. and Vanneman, M. (2005) Medicaid in New Jersey: Options for reform. Hall Institute of Public Policy, New Jersey, 1-12.

[26] Fossett, J.W. and Burke, C.E. (2010) Medicaid policy and long-term care spending. Health Policy Research Center. The Nelson A. Rockefeller Institute of Government, University at Albany State University of New York.

[27] Cappell, J., Herrmann, N., Cornish, S. and Lanctot, K.L. (2010) The pharmacoeconomics of cognitive enhancers in moderate to severe Alzheimer's disease. CNS Drugs, 24, 909-927. doi:10.2165/11539530-000000000-00000

[28] Gilligan, A.M., Malone, D.C., Warholak, T.L. and Armstrong, E.P. (2012) Health disparities in cost of care in patients with Alzheimer's disease: An analysis across 4 state Medicaid populations. American Journal of Alzheimer's Disease and Other Dementias, 28, 84-92.

[29] Kruse, R.L., Mehr, D.R., Boles, K.E., Lave, J.R., Binder, E.F., Madsen, R., et al. (2004) Does hospitalization impact survival after lower respiratory infection in nursing home residents? Medical Care, 42, 860-870. doi:10.1097/01.mlr.0000135828.95415.b1

[30] Loeb. M., Carusone, S. C., Goeree, R., Walter, S.D., Brazil, K., Krueger, P., et al. (2006) Effect of a clinical pathway to reduce hospitalizations in nursing home residents with pneumonia: A randomized controlled trial. Journal of the American Medical Association, 295, 2503-2510. doi:10.1001/jama.295.21.2503 
[31] Luchins, D.J. and Hanrahan, P. (1993) What is appropriate health care for end-stage dementia? Journal of the American Geriatrics Society, 41, 25-30.

[32] Morrison, R.S. and Siu, A.L. (2000) Survival in end-stage dementia following acute illness. Journal of the American Medical Association, 284, 47-52. doi:10.1001/jama.284.1.47

[33] Beusterien, K.M., Thomas, S.K., Gause, D., Kimel, M., Arcona, S. and Mirski, D. (2004) Impact of rivastigmine use on the risk of nursing home placement in a US sample. CNS Drugs, 18, 1143-1148. doi:10.2165/00023210-200418150-00008

[34] Lopez, O.L., Becker, J.T., Wisniewski, S., Saxton, J., Kaufer, D.I. and DeKosky, S.T. (2002) Cholinesterase inhibitor treatment alters the natural history of Alzheimer's disease. Journal of Neurology, Neurosurgery \& Psychiatry, 72, 310-314. doi:10.1136/jnnp.72.3.310

[35] Knopman, D., Schneider, L., Davis, K., Talwalker, S., Smith, F., Hoover, T., et al. (1996) Long-term tacrine (Cognex) treatment: Effects on nursing home placement and mortality, tacrine study group. Neurology, 47, 166177. doi:10.1212/WNL.47.1.166 